Paediatric Burns Unit at Our Lady's Children's Hospital in Crumlin, on admissions to the unit with burns $\geq 20 \%$ TBSA. We look at their mechanism of Injury (scald vs. flame), TBSA as $\mathrm{a} \%$, and length of hospital stay, as well as long term outcomes where available.

\section{P5 ACCIDENTAL TRANSDERMAL FENTANYL EXPOSURE IN CHILDREN - A REVIEW OF THE LITERATURE}

Fiona Finlay*. Virgin Care, Bath, UK. Wiltshire CCG, Devizes, UK

10.1136/archdischild-2019-epa.361

Introduction and aims Fentanyl is a highly potent opioid. Accidental transdermal fentanyl exposure resulting in fatalities has been reported in children. Discussion of the topic prompted us to review the literature and disseminate 'lessons learned'.

Methods Literature review

Results A 25 microgram/hour fentanyl patch is equivalent to an oral morphine dose of $60-90 \mathrm{mg}$ in 24 hours

Patches worn for 3 days and discarded may still contain $50 \%$ of original drug - enough to cause serious harm/death

Infants, children and pets are at higher risk from accidental exposure while exploring their surroundings touching, tasting and chewing things

Patches may be ingested - there is more than a 30-fold increase in absorption from the buccal mucosa if chewed compared with the transdermal route. Swallowing an intact patch results in less rapid drug release compared with chewing, but systemic absorption is still significant

Patches may accidentally stick to a child's skin - patients should be informed that co-sleeping with their children is risky as patches may transfer from adult to child

Children enjoy applying stickers, plasters and 'tattoos' and may deliberately stick on patches if found

Used patches should be disposed of carefully and not be put in a wastepaper bin where children may find them

Patches may be poorly adherent if skin is wet, sweaty, hairy or oily - check regularly that patch has not fallen off. May cover the patch with adhesive film to ensure it stays on

Discarded patches should be folded putting the sticky sides of each patch together so that it sticks to itself. They should then be wrapped in paper or plastic before disposal

Identifying early signs of fentanyl exposure is challenging as many are non-specific in children eg lethargy may be confused with tiredness

Pharmacists should dispense patches in child-resistant packages

Conclusion It is crucial to educate patients about appropriate use of fentanyl patches, including careful application, storage and disposal. Education should be provided face-to-face.

Action is required by individual practitioners, health care and professional organizations, public policy agencies, pharmaceutical companies and advocacy groups to try to ensure that further deaths do not occur due to accidental exposure to transdermal fentanyl

\section{P6 \\ FACTORS ASSOCIATED WITH COMPLIANCE WITH NUT/ SEED REINTRODUCTION FOLLOWING A NEGATIVE FOOD CHALLENGE - A COHORT REVIEW FROM A SPECIALIST PAEDIATRIC ALLERGY UNIT}

${ }^{1,2}$ Roslyn Tarrant*, Ian Gregory ${ }^{1},{ }^{1}$ Roisin Fitzsimons. ${ }^{1}$ The Children's Allergy Service, Evelina London Children's Hospital. Guy's and St. Thomas' NHS Foundation Trust, London, UK; ${ }^{2}$ Coombe Women and Infants University Hospital, Dublin, Ireland

10.1136/archdischild-2019-epa.362

Introduction Selective nut/seed eating has become standard practice in allergy units across Europe, with studies suggesting there is potential for patients allergic to one nut or seed to incorporate others into their diet. To minimize cross-contamination risk, our unit guidelines provide standards for 'safe selective nut/seed eating' however the compliance rate with such guidelines is unknown. The aim of the current study is to assess patient compliance with nut/seed reintroduction, and examine the factors predictive of full compliance.

Methods Eligible patients who had a negative food challenge to a nut/seed in the preceding 2 and 12 months at a single paediatric allergy unit were identified from an institutional database, and followed up via a telephone intervieweradministered questionnaire in June 2018. Patient compliance with nut/seed reintroduction advice in four domains including frequency of eating (i.e. $\geq 2$ times/week), type of food consumed (i.e. whole/ground from single nut/seed pack), age-appropriate portion size, location of eating (i.e. in the home only) was assessed; 'full' compliance denotes compliance with all four domains combined. Data were collected on patient receival of support/information, barriers to compliance, and parental perceptions of the reintroduction experience.

Results From 141 eligible patients, 100 (70.9\%) consenting participants were successfully followed up at either 2 $(54 \%)$ or $12(46 \%)$ months post-challenge; median age was 3.8 years. Only $17 \%(\mathrm{n}=17)$ of the sample fully complied with all four domains combined. The highest compliance rate was in the 'location' domain (70\%); 39\% of patients complied with recommended 'portion size'. The most prevalent reason for not eating the nut/seed as frequently as recommended included 'the child not liking the taste of the food' ( $\mathrm{n}=24 ; 41.1 \%)$. Fifty five percent $(\mathrm{n}=55)$ of parents reported to receiving hospital literature on nut/seed reintroduction; $15 \%$ spoke with a dietitian regarding nut/seed reintroduction advice. Parental agreement with the statement 'my child likes eating this food' was independently associated with full compliance with nut/seed reintroduction advice (aOR 5.6, 95\% CI 1.55-20.8, $P=0.009)$.

Conclusion This study demonstrates that compliance with local guidelines on nut/seed reintroduction is poor. There is a need to ensure that all patients receive optimal support/information on the day of the food challenge. More thorough assessment prior to the challenge of whether patients and their families are suitable for, and committed to selective nut/seed eating, may result in improved compliance. 